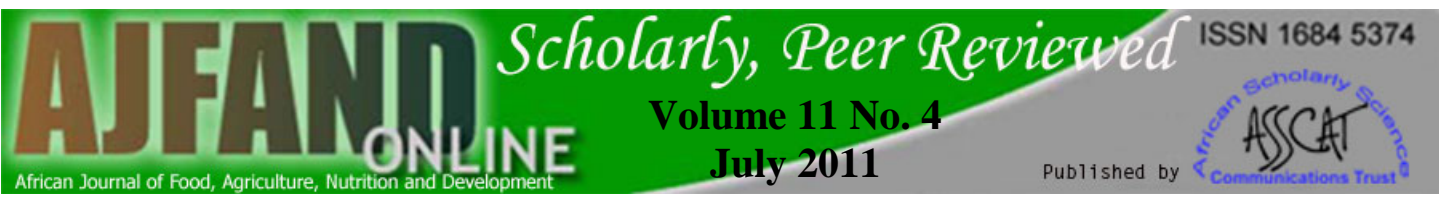

\title{
GROWTH OF CHILDREN RECEIVING A DEHYDRATED POTATO-SOY PROTEIN CONCENTRATE OR CORN-SOY BLEND AS PART OF A FOOD AID PROGRAM IN NORTHERN SENEGAL ${ }^{\dagger}$
}

\section{Taren $\mathrm{D}^{1^{*}}$, Almony $\mathrm{C}^{1}$, Tecle $\mathrm{S}^{1}$, Navarette $\mathrm{L}^{1}$, Ernst $\mathrm{K}^{1}$, Menard $\mathrm{S}^{2}$, Diop $\mathrm{M}^{2}$ and A Wele ${ }^{2}$}

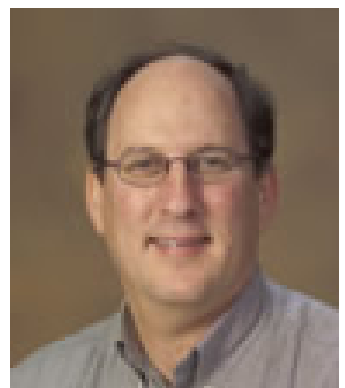

Douglas Taren

* Corresponding author email: $\underline{\text { taren@email.arizona.edu }}$

${ }^{1} \mathrm{Mel}$ and Enid Zuckerman College of Public Health, University of Arizona,1295 N Martin Ave, POBOX 245163, Tucson, AZ 85724.

${ }^{2}$ Counterpart International, Senegal Office, Point E, Boulevard de L’Est, AlleesThiernoSeydouNourou Tall, BP 248, Dakar-fann, Senegal.

\footnotetext{
${ }^{\dagger}$ This study was conducted in cooperation with the Counterpart International Senegal National Office. Financial support was provided by the United States Potato Board. The soy protein concentrate was provided by the Solae ${ }^{\circledR}$ Company. The vitamin premix was provided by Fortitech ${ }^{\circledR}$. The assessment of the blending and nutritional composition of the PSB was provided by Purina ${ }^{\circledR}$. Results of this study were also presented at the International Congress of Nutrition, Bangkok, Thailand October 8-11, 2009.
} 


\section{ABSTRACT}

Rations distributed by food aid programs are intended to improve the growth of undernourished children. In practice, food programs target individual children and provide a supplement to the family that is intended to increase the energy and nutrient intake of undernourished children. Multiple food rations are available yet few studies have compared their differential effect on the growth of children. The objective of the study was to compare growth in undernourished Senegalese children who received a newly developed dehydrated potato-soy protein concentrate blend (PSB) to those supplemented with the currently available corn-soy blend (CSB). The first child at each site was randomly assigned to receive PSB or CSB and subsequent children alternately received PSB or CSB. Eligibility for obtaining the food ration was based on criteria determined by the USAID (P.L. 480) Title II Food Aid Program. Children received iso-caloric amounts of the two supplements each month $(23,000 \mathrm{kcals})$. Weight, height and mid-upper arm circumference (MUAC) were taken over a fourmonth period. Z-scores were calculated for weight-for-age (WAZ), weight-for-height (WHZ) and for length/height-for-age measures (HAZ).The study was conducted at 7 clinics which served as food distribution sites in northern Senegal. The study enrolled 348 children 18-56 months old with a weight-for-age z-score below the "yellow" zone of the locally available growth chart (equivalent to WAZ $\leq-1.0$ ). WAZ and HAZ significantly increased over time but there was no difference between the two ration groups. In a subset of 280 children (145 PSB, 135 CSB) who attended all four appointments and received the full complement of ration, there was significant and equivalent increase for both groups in WAZ and WHZ. These findings indicate that children participating in the food aid program significantly improved their growth over a four-month period. Using the new PSB as a ration had the same impact on growth as the standard CSB and required less fuel to prepare.

Key words: food aid, anthropometrics, randomized trial 


\section{INTRODUCTION}

Infant and childhood mortality in Senegal are estimated at 59/1,000 and 114/1,000, respectively [1]. Acute respiratory infections, diarrhea, and malaria are the most common causes of infant and under-five mortality in Senegal [2]. Malnutrition which compromises child health is also prevalent in Senegal with 14\%of children under-five years of age having a weight-for-age z-score(WAZ) between -2.0 and -3.0 in 2007, and an additional $3 \%$ of children having a WAZ $\leq-3.0$ [1]. Chronic under-nutrition was estimated to be at $16 \%$ of Senegalese children under 5 years of age with a length/height-for-age z-score (HAZ) $\leq-2.0$ in 2007 (moderate and severe stunting). Acute malnutrition was also present in $8 \%$ of the under five year old children [1]. Work by Idohou-Dossou et al.[3] suggests that stunting remains a prominent feature in Senegalese children who suffer from malnutrition. Urban and rural differences also exist in Senegal regarding the prevalence of under-nutrition. In 2000, it was estimated that $9.1 \%$ of rural children had a WHZ $\leq-2.0$ compared with $7.0 \%$ of children in urban areas [4].

Under-nutrition is an important factor in the death of many young Senegalese children contributing to $31 \%$ of all deaths in under- five year olds [2]. Although less common, severe malnutrition still contributes to $5 \%$ of under-five deaths [2]. However, even mild malnourishment can increase the mortality risk [5] and in Senegal where moderate malnutrition is highly prevalent it is implicated in up to $84 \%$ of the deaths associated with malnutrition [2]. Thus, programs that improve the nutritional status of not only malnourished children but children who are at risk for malnutrition should decrease the under-five mortality rate [6].

Food aid programs including those to improve maternal and child health programs and to provide humanitarian assistance in times of emergencies are designed to improve the nutritional status of undernourished children and prevent infant and childhood deaths [7]. The United States Agency for International Development (USAID), the World Food Program (WFP) and other aid organizations support projects that provide food directly to individuals including humanitarian feeding, food-for-work, maternal and child health programs to supplement the diets of pregnant and lactating women and children $<5$ years of age, child survival programs, and school feeding programs. The foods that are provided are based on grains and pulses including whole grains (corn, rice, sorghum, bulgur and wheat, dried and split beans, peas, and lentils). Some products are already milled, fortified or blended with soy. The list of available foods is still relatively limited in number and their costs are subject to the fluctuation in the grain markets [8]. Unfortunately, there are few studies that have compared the effect of these supplements on the nutritional status of their target populations $[9,10]$.

The purpose of this study was to compare the growth of targeted children who received a newly developed ration, a dehydrated potato granule-soy protein concentrate, (PSB) to children who continued to receive corn-soy blend (CSB) as part of a monthly ration. Differences in the weight, height and mid-upper arm circumference over a four-month period were measured along with z-scores for

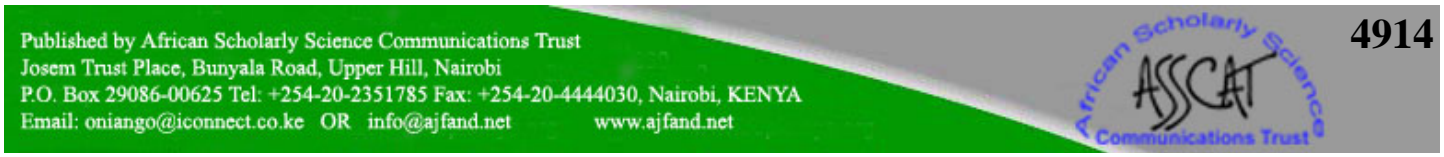


weight-for-height, height-for-age and weight-for-height. The analyses were conducted to determine the changes in the whole group and a secondary analysis was conducted to determine how the growth of the children varied when the children had received the supplement on all four occasions and missed no appointments.

\section{METHODS}

\section{Study Design}

This study was a randomized trial within a currently functioning food aid program. Children that participated in a current food distribution program with Counterpart International (CPI), a non-governmental organization working in the northern Senegal region, were recruited to be in this study. The existing program provided a ration of lentils, oil and CSB on a monthly basis for children who were eligible for the program. Additionally, the anthropometric measurements of the children were taken at the time of each food distribution. For the purpose of this study, all children had their anthropometric measures taken at baseline to confirm they met the criterion to be in the food aid program. The first child at each clinic was randomized to receive either PSB or CSB as part of the monthly ration with subsequent children alternately being assigned to one of the two rations. Thus, PSB was substituted for the CSB within the food ration. After the initial baseline visit, participants were asked to return each month over the next four months to receive their child's monthly ration of food aid and to have their anthropometric measurements taken and recorded. The study was conducted from the beginning of November 2008 and ended in March 2009.

\section{Population}

The location for this trial was the Department of Podor in the Saint Louis region of northern Senegal. The Department of Podor is rural area of $12,947 \mathrm{~km}^{2}$ and has a population of 329,379 inhabitants mostly belonging to the Pular ethnic group. Traditionally, Pular people are pastoralists that tend to live in compounds or huts in scattered villages. The Route Nationale region is the area $10 \mathrm{~km}$ south and $10 \mathrm{~km}$ north of the Route Nationale paved highway. All sites were selected from Route Nationale to create a more comparable sample. Additionally, populations in neighboring regions of Dieri and Walo were more migratory spending weeks away to herd cattle or farm distant croplands.

In order to be eligible for the trial, villages had to be a site for the Counterpart International's (CPI's) Maternal and Child Health Nutrition (MCHN) program supported by the USAID Food-for-Peace program and not more than $20 \mathrm{~km}$ from CPI's office in Ndioum. Seven villages were randomly chosen from the 13 meeting the eligibility criteria: Bode, Diomandou, Toulde Galle, Sinthiou Penaka, Doumga Lao, Gawdi Gotti, and Olol Diaobe.

\section{Recruitment and Randomization}

The goal was to recruit at least 300 underweight to severe malnourished children, 1854 months old at the seven sites selected for our study. The sample size considerations for this study were based on the ability to illustrate a difference in the changes for z-score measurements for weight-for-age (WAZ), and weight-for-height

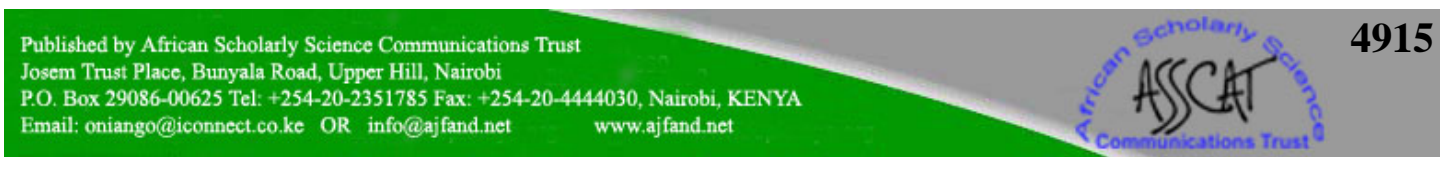


(WHZ). A significant difference in the change in z-score measures was assumed to be an increase by a value of 0.5 for one group and 0.25 for another group because the estimated standard deviations around these changes would be larger than the mean difference at a value of 0.7 . Setting alpha at 0.5 and power at 0.8 a sample size of 124 children per group determined as needed to achieve statistically significant results.

On recruitment day we used the weight-for-age growth chart Counterpart International uses to determine the child's nutritional status at baseline. If the child's weight fell in the yellow or red zones, a z-score approximately $\leq-1.0$, then the child was considered eligible for the program and the family was given a food ration for the child. To ensure independent observations, the youngest child in the family who met the entry criterion was eligible to be in the study if more than one child had a low WAZ. Children were excluded from the study if they had edema or were considered to have kwashiorkor.

Clinic attendance varied and some sites had more recruits than others. Additionally, there was disproportionate distribution of CSB participants at one site when supplies of PSB ration ran out on its first day of distribution. A total of 345 children were recruited for the study. 178 were assigned to the CSB group and 167 to the PSB group.

\section{Ethical Considerations}

At the start of the study, all mothers and guardians for the children were read a disclaimer form that described the study and verbal consent was obtained for children who participated in the study. The study protocol was approved by the University of Arizona Institutional Review Board (IRB) and the Podor Health District Office where the study was conducted.

\section{Food Supplements}

The PSB was a combination of dehydrated potato granules and a soy protein concentrate $\left(\mathrm{PROCON}^{\mathrm{TM}} 2000\right)$ in a $6.25: 1$ ratio. The PSB provided $349 \mathrm{kcal} / 100 \mathrm{~g}$ compared with $376 \mathrm{kcal} / 100 \mathrm{~g}$ for the CSB. The protein contents for the two supplements were similar with $18.5 \mathrm{~g} / 100 \mathrm{~g}$ of protein in the PSB compared with $17.2 \mathrm{~g} / 100 \mathrm{~g}$ of protein in the CSB. However, the fat content in the CSB $(6.9 \mathrm{~g} / 100 \mathrm{~g})$ was greater than the PSB $(0.9 \mathrm{~g} / 100 \mathrm{~g})$. To ensure an iso-caloric distribution of the supplements $6.6 \mathrm{~kg}$ of the PSB was given to families each month while $6.2 \mathrm{~kg}$ of the CSB was distributed. As for the CSB, the PSB was fortified (Table 1) with a vitaminmineral premix (Fortitech ${ }^{\circledR}$ ). The premix included vitamin A, riboflavin, folic acid, vitamin B12, iron (iron fumarate), calcium (calcium carbonate) and the nutrient composition was directly measured by Purina ${ }^{\circledR}$ Labs. It was also determined that the final product was effectively mixed and there was no settling or separation of the constituents by taking multiple samples from various places within bags for analyses. At the time of the food distribution, families from both groups also received two liters of vitamin A enriched palm oil, and $6.0 \mathrm{~kg}$ of lentils.

Families that received the PSB were also provided a demonstration on how to use it to make porridge. The PSB porridge was based on World Vision's Broken Bread 
Program's Recipe for CSB porridge and modified for consistency and taste [11]. The CSB porridge recipe used $130 \mathrm{~g}$ CSB, 750-1000g water, $13.6 \mathrm{~g}$ oil, $3 \mathrm{~g}$ salt and $100 \mathrm{~g}$ sugar or to taste. The PSB porridge was made with 290g PSB, 1250-1500g water, 15g oil, $5 \mathrm{~g}$ slat and $120 \mathrm{~g}$ sugar or to taste. A $100 \mathrm{~g}$ serving was calculated to provide $97.0 \mathrm{kcal}$ consisting of $12 \%$ protein, $9 \%$ fat and $79 \%$ carbohydrates. Compliance to the use of the food supplements was monitored with home visits. A total of 80 homes were visited during the study and these visit made visual observations and verified that rations were not shared with other families.

At the start of the study, a plan was laid out to minimize any sharing of supplements between families. The field staff provided instructions to the families that the use the food supplements was only for the children who were being targeted by the program. Cross-contamination was controlled by limiting one child per mother to enter the study. However, an additional ration was also given if a second child was also malnourished but the growth of this child was not monitored for this study. It was clear it would be too difficult to try to keep track of multiple children in the same household and make sure they all received the same type of ration (CSB or PSB). More importantly, families were told that they would be expelled form the study for selling or exchanging the food for other items. However, this study did not directly measure the substitution effect of food aid. Sharing of food within households surely happened and was documented with home visits and interviews, but the extent is not known. It was not known that in $80 \%$ of the homes visited, the supplement was used within the first 2 weeks of the month.

\section{Data Collection}

Trained community health workers obtained basic demographic information from the mothers including child's name, mother's name, date-of-birth, sex, and village of residence. The community health workers questioned the mothers in Pular or French and then recorded their responses in French. The mothers were also questioned about the child's recent history of infection, specifically if the child had had any episodes of diarrhea, fever, or respiratory illness within the previous week and the responses were recorded as yes or no. In addition, they were asked when the last time the child had taken anti-parasitic medication as the maternal and child health program provided deworming medicine every six months.

After the questionnaire was completed, the child's measurements were taken as described by the World Health Organization (WHO) [12]. Children were weighed wearing light clothes to the nearest $0.1 \mathrm{~kg}$ using a digital SECA ${ }^{\circledR} 872$ scale that used load cells. Weights were recorded on the child's intake form that also contained information concerning identity and village of residence. Height measurements were taken using a Schorr ${ }^{\circledR}$ measuring board in order to determine a child's height or length. If the child was less than 24 months of age, then the child's length to the nearest mm was taken. If the child was greater than 24 months of age or older, then the child's height to the nearest millimeter was taken. MUAC measurements were also taken to the nearest millimeter using a measuring tape. 
Many of the mothers were not certain about their child's date-of-birth, recent history of infection, or the last time their child received anti-helminthic medication. The inaccuracy of birth dates was a main concern because two out of three of the indicators used for malnutrition rely on accurate age information (weight-for-age and length/height-for-age). Some mothers believed that their child was more likely to be in the study if they were younger and thus may have understated their ages. Interestingly, this would have disqualified many children from the study due to artificially increasing their WAZ. We were able to minimize this problem by using the expertise of the clinic personnel who had access to birthdates from clinic records. It was also possible to determine inaccuracies after calculating z-scores and determining any incongruence between WAZ, HAZ and WHZ values. This allowed the research team to follow-up with mothers and the clinic the next month to make the appropriate changes to their age in our database and to re-calculate z-scores.

\section{Data Management and Analysis}

EPIINFO (Version 3.5.1) was used to enter data from questionnaires. The ANTHRO program within EPI INFO (Version 1.02) version was used to calculate the anthropometric z-scores based on the WHO/CDC standards [13]. The EPIINFO ${ }^{\circledR}$ data set was then transferred to a Stata ${ }^{\circledR}$ statistical software package (Version 8.2) which was used for the statistical analysis. Mean values for WHZ, WAZ, HAZ and MUAC were compared for the two groups at baseline and the changes in the anthropometric z-scores. A longitudinal mixed effects model was used to analyze the data using the xtmixed command and having age at entry, sex, and location as the fixed variables. Growth was assessed over the four measures and we checked for a ration by period interaction. Random and fixed affect models were compared. The number of missing visits was determined to be random and not different between the two ration groups. Only 4 children missed a total of 2 visits, the others missed only 1 visit and these were evenly distributed across visits 2, 3 and 4.A second analysis for this report is limited to a subset of 280 children with complete records. The decision to restrict an analysis to this group was made to ensure that the children compared had received equivalent amounts of ration over the four month period. Comparisons within and between groups for this subset were made with ANOVA to control for health status at baseline, location, sex, and age.

\section{RESULTS}

The study recruited 345 children with 178 assigned to receive CSB supplemental rations and 167 assigned to children assigned to receive the PSB supplemental rations. The mean age was $35.7 \pm 10.7$ (SD) months (range 18-57 months) and 57.1\% were female and $42.9 \%$ were males. There were no significant differences in these values between the two groups. The number of missed visits appeared random and there was no difference in the distribution of missed visits between the two groups. Tables 2 and 3 present the initial mean anthropometric measurements based on the sex, age group, and initial health status of for the PSB and CSB groups. There were no significant differences in these values. Log likelihood models determined that a longitudinal fixed-effect model was the best to show changes in growth compared to random-effect models. Time period was associated with a significant increase for

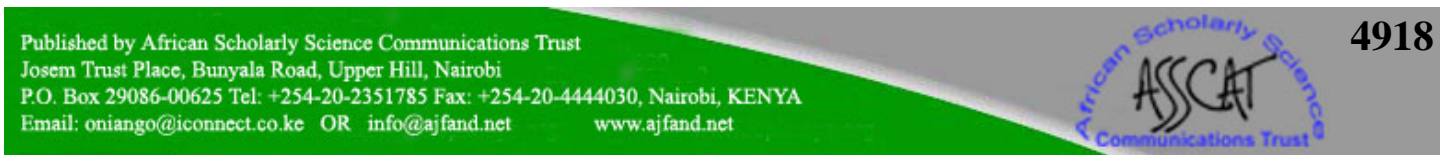




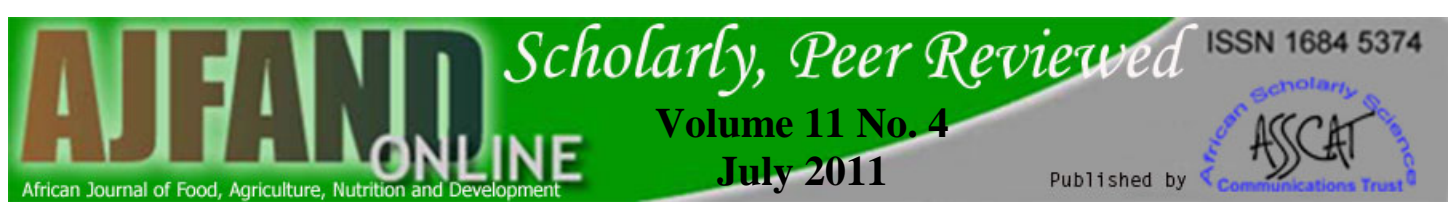

weight, height, MUAC, WAZ and HAZ but not for WHZ. Ration type was not associated with the growth of children in any of the models. Older children had a greater increase in their weight, height and MUAC during the study. However, younger children had the greatest gain for HAZ. Boys had the greatest gain in weight, and height and for WHZ, but not for any of the other anthropometric measures.

Figure 1 illustrates the children who attended 100\% of all the visits [14].In total, 33 children from the CSB and 32 children from the PSB group were dropped from the sub-study for having missed one or more visit. Many of these children were refugees from Mauritania and were reported as repatriated to their country. There were no significant differences in mean age, sex, baseline anthropometric measures or baseline reports of diarrhea, respiratory infection or fever between those who completed all aspects of the study and those who did not.

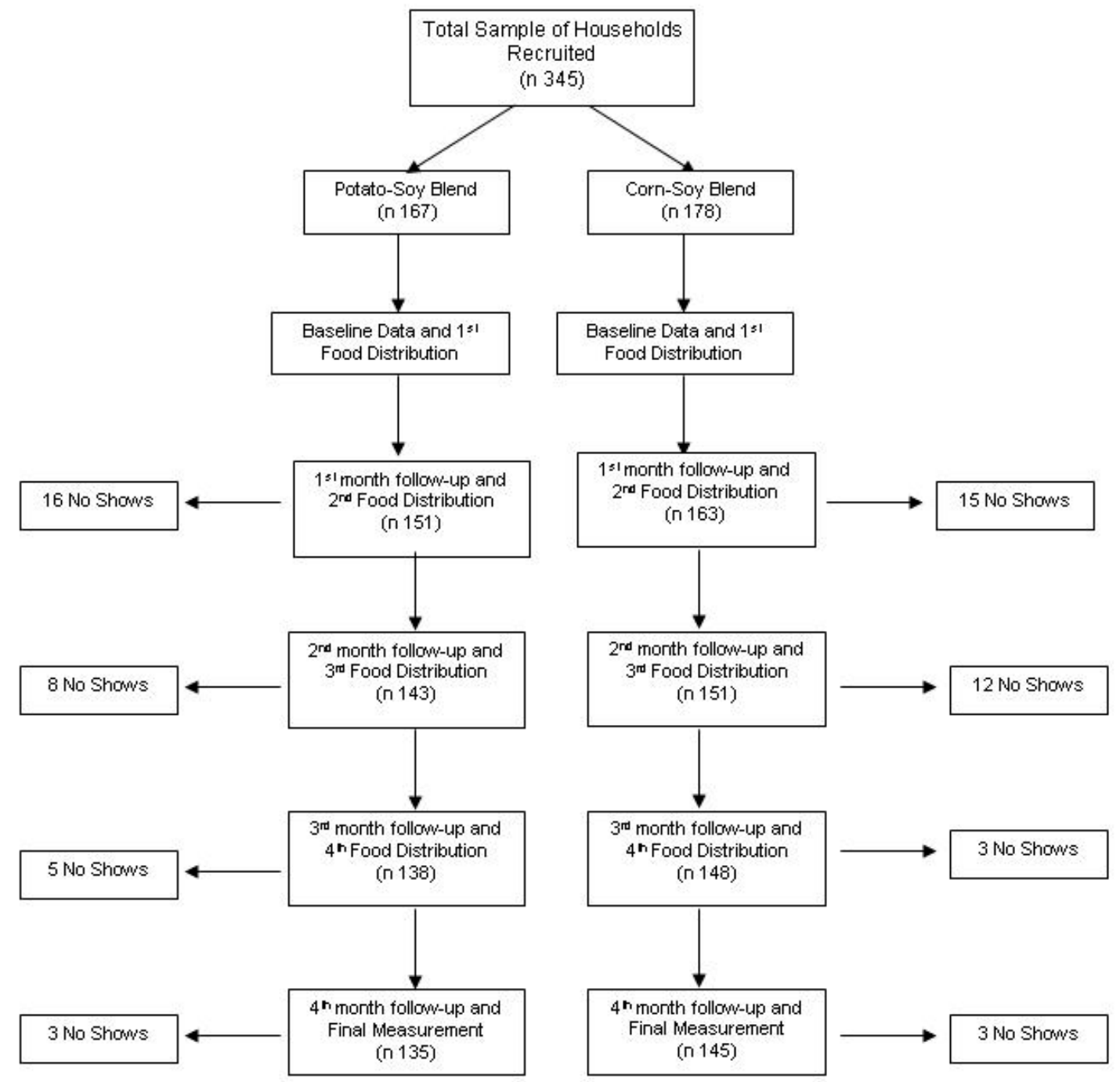

Figure 1: Consort diagram indicating children who participated in the study

There were few differences between the intervention groups at baseline for this subset (Table 4). The mean WAZ for the CSB group was $-2.46 \pm 0.05$ (SE) compared with - 
$2.45 \pm 0.05$ (SE) for the PSB group. The only significant difference was that the CSB group had a slightly greater prevalence of fever at baseline. However, this pattern did not continue into the following months and no significant differences in the rates of infection between the two groups were seen at any other time.

The mean WAZ, WHZ and HAZ values increased across all children and within each supplement group (Table 5). The mean MUAC measurement also increased across all children but there was no significant difference within either group. The growth between boys and girls were nearly identical regarding the changes in their anthropometric z-scores as a total group or within the supplement groups. Children with low initial WAZ (z-score $\leq-2.0$ ) significantly increased their WAZand WHZ values more than those whose initial values with higher scores (data not shown). Nonetheless, children who had an initial WAZ that was $>-2.0$ also significantly increased $(\mathrm{p} \leq 0.05)$ their WAZ by 0.11 units (SE 0.04). Similarly, children with an initial WHZ $>-2.0$ significantly increased $(\mathrm{p} \leq 0.01)$ their WHZ by 0.13 units (SE 0.04 ) over the course of the study. There was no difference in the HAZ for those children who had an initial HAZ > -2.0.

The percent of children with a WAZ $\leq-2.0$ significantly $(\mathrm{p}<0.01)$ decreased from $79.3 \%$ to $62.9 \%$. Similarly, there was a significant decrease $(\mathrm{p}<0.01)$ in the percent of children with a WHZ $\leq-2.0$ from $45.7 \%$ to $31.1 \%$ over the four-month period. The percentage of children with low HAZ values remained the same during this time period at $32.9 \%$.

In regards to the overall purpose of this study, the absolute changes for the mean weight, height and MUAC values were not significantly different between the two groups over the study period (Figure 2). Similarly, there was no significant difference in the changes for the mean WAZ, WHZ, and HAZ values between the two supplement groups (Figure 3). 
(a)

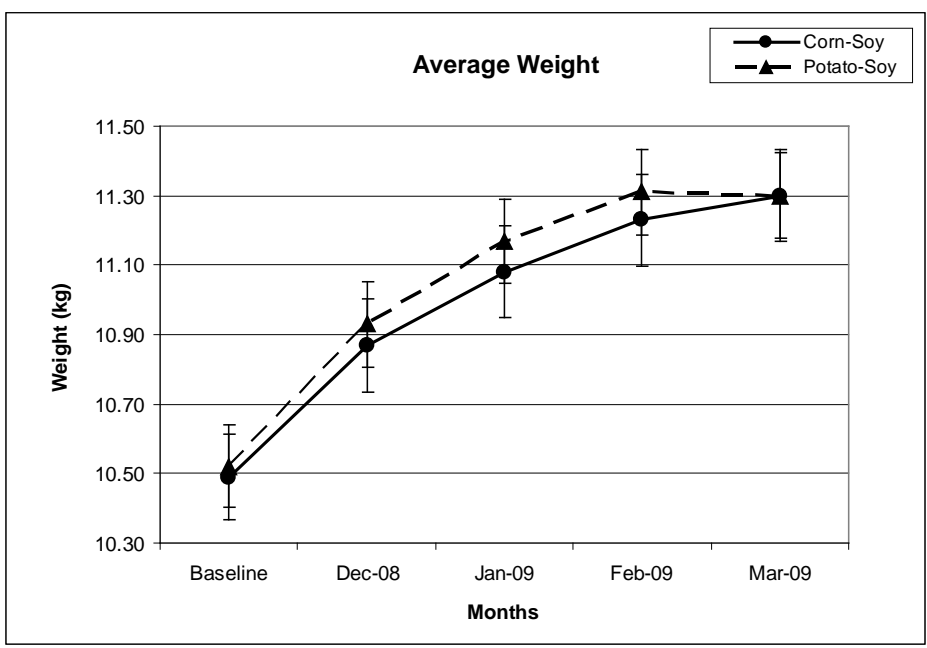

(b)

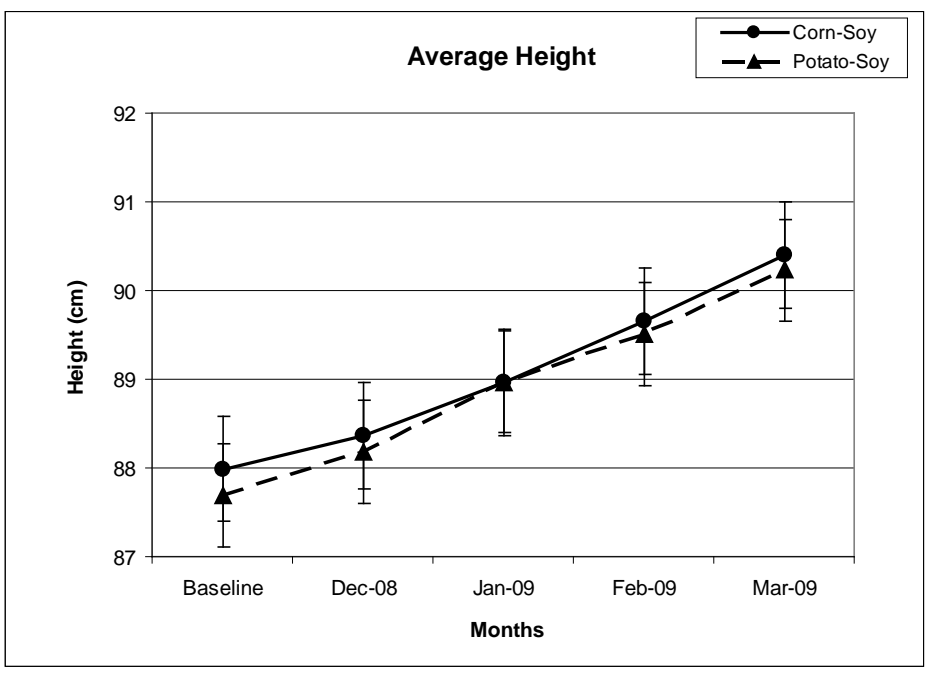

(c)

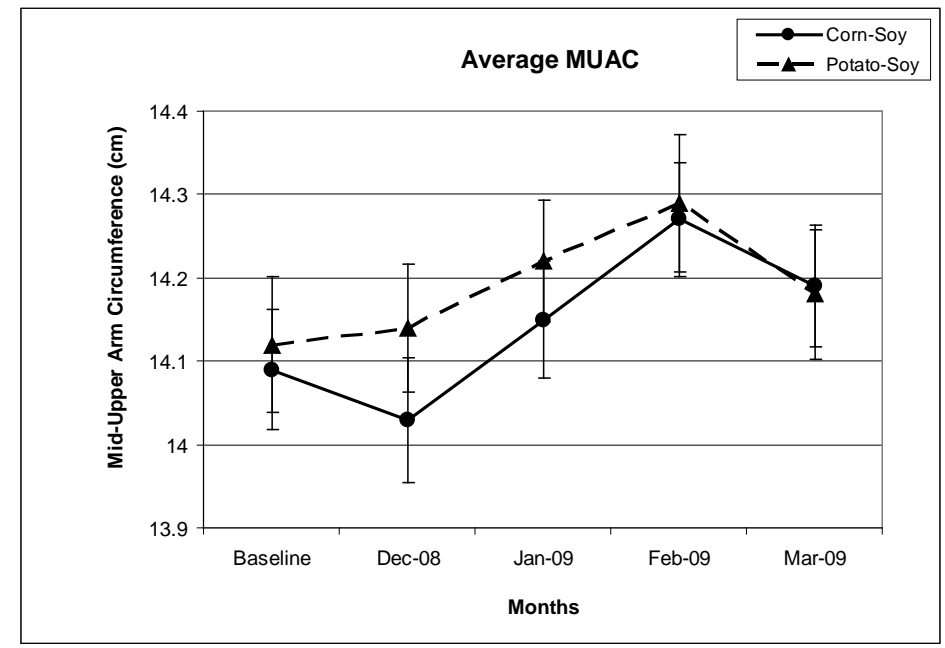

Figure 2: Changes in weight, height and mid-upper arm circumference (MUAC) 


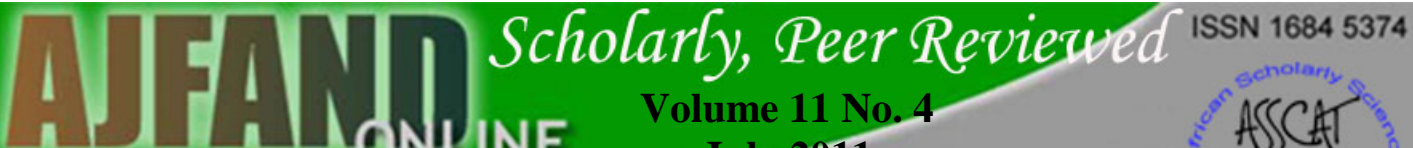

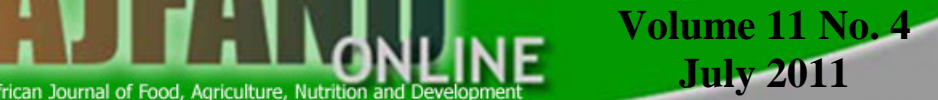

(a)

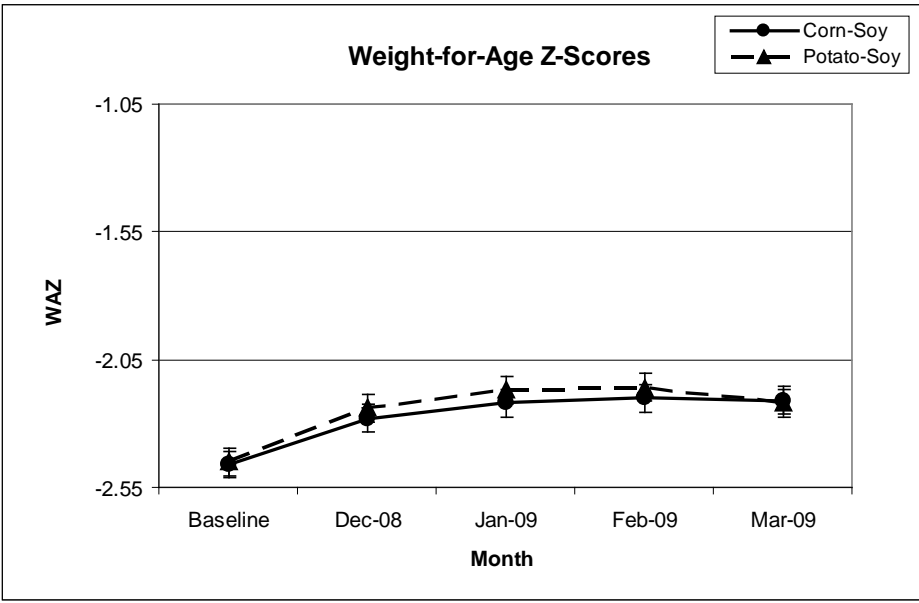

(b)

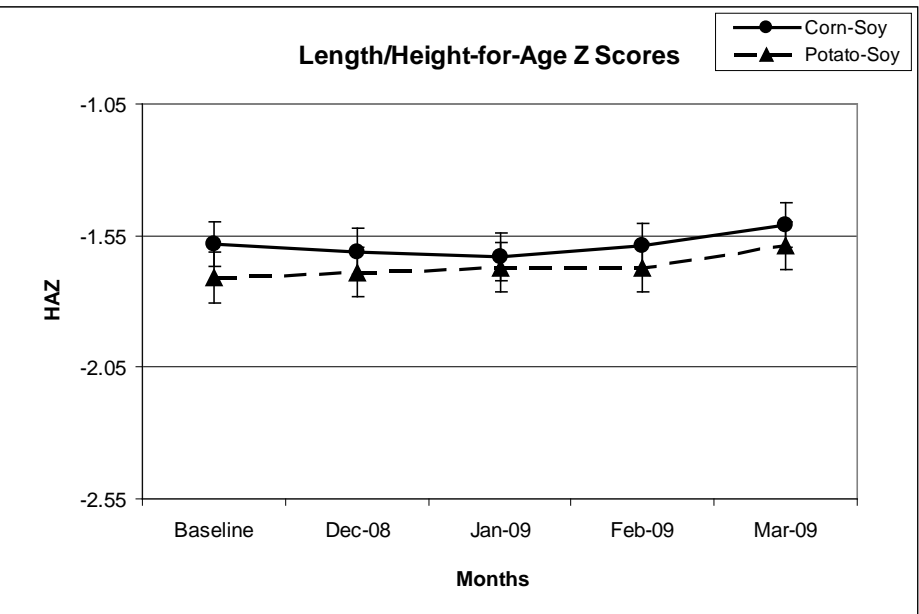

(c)

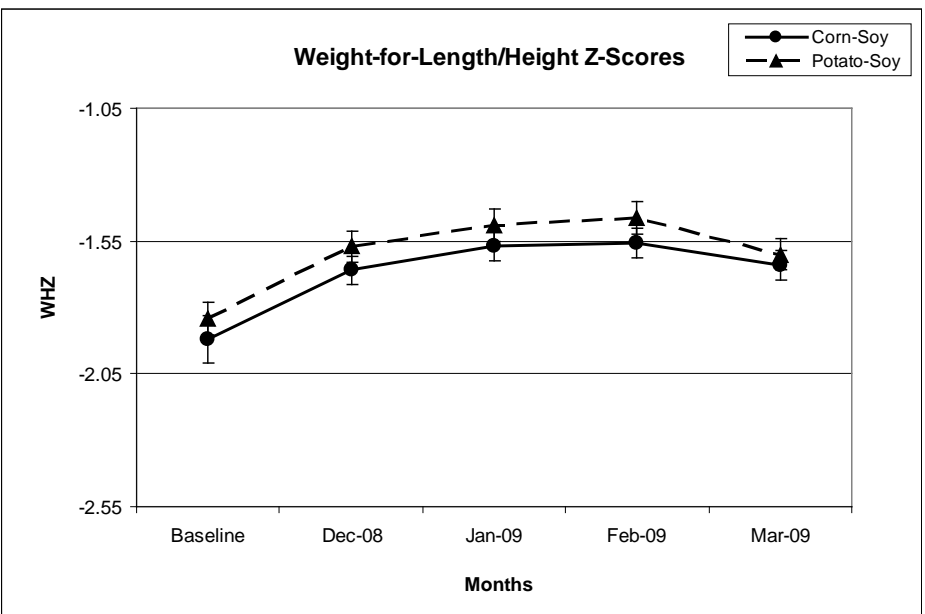

Figure 3: Changes in anthropometric z-scores 


\section{DISCUSSION}

The study was conducted with children who lived in poverty, were at risk for infectious disease, lacked an appropriate quantity and quality of food and qualified for a USAID funded food aid program. This study focused on the direct recipients of food aid, malnourished children whose food resources were supplemented with additional food. The primary outcomes indicated that the growth of children improved by participating in the program and that there were no differences between the two rations in regards to the improvement in the growth of the children.

Evidence exists that food aid has not been a disincentive for food production for the recipients of food aid [15]. The current study provides evidence that providing food supplements appears to contribute positively to children's growth over the four-month period. The current results provide evidence that food aid programs that distribute monthly rations can have a significant beneficial effect on the lives of children. The improvement in growth was, at least, partly due to targeting undernourished children [17-19]. The positive outcomes from this study in the overall growth of children, does support that targeted food supplement programs can be an important component of a comprehensive approach to improving the nutritional status of a region or nation when combined with improved primary care, increased water and sanitation, and broad economic reforms that focus on poverty reduction [20].

This study also directly responded to the need for additional and improved fortified blended foods [21]. Most studies at this time are comparing the composition of blended foods but not how they differ in their effect on the growth of children [21]. Since this study was conducted through the local public health system, the community approach to managing malnutrition was incorporated throughout this study as recommended by WHO [22]. The use of a potato-based supplement also had a high value within this population and was a culturally appropriate alternative to the CSB. It was well accepted because potatoes are often part of the diet but only when families can afford to purchase them.

The PSB was also chosen as a food that would be more easily digested since it has less fiber than the CSB and lead to less discomfort by children. Families used less fuel to prepare the PSB compared with the CSB since the cooking time is significantly reduced with the PSB. This was consistently reported as an advantage for the families who used the PSB.

One could extend these results and suggest that creating better local agriculture and manufacturing infrastructure to increase local availability of potato and soy products could be encourage to develop an industry for producing PSB. Potato, especially sweet potatoes are grown extensively throughout Africa. It also suggests that if a region or country goes this direction with their development plans that they also need to develop methods to decrease post-harvest loss that can allow these foods to be used at a later date [23-25]. 


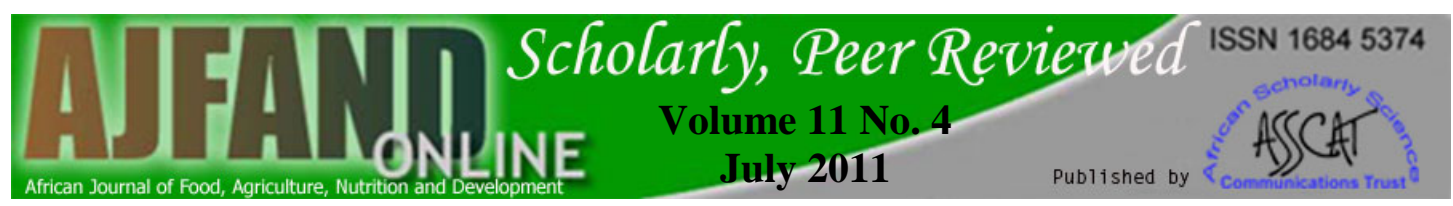

The primary purpose of this study was to compare the two food rations and the study design was chosen to evenly distribute any bias that could have occurred. The major strength of this study lay in the fact that it was an applied study on the effectiveness of the two rations within an on-going food aid program. Even with the randomization, we determined that it would be important to control for several fixed variables. Previous studies have shown the response to interventions differ by initial age and sex of the children. We also controlled for current health status due to its association with future growth [26].

This study design provided for balance with regards to the children's baseline characteristics. Researchers do not have any reason to believe that sharing of food or the food substitution would be different between the two groups. This analysis was also restricted to children who received their food supplements at each visit over the four-month study period. Knowing that both groups had the same dose of the supplements, the results from the study support the outcome that both groups had an equal positive effect on the growth rate of the sample population. It was a field-based study and therefore the results can be used to show the effectiveness of the intervention beyond what would be known about the efficacy from a random clinical trial. Thus, the results may be extrapolated to have similar outcomes for children who participate in targeted food distribution programs.

\section{CONCLUSION}

This study indicated that the growth of targeted children who participated in a food aid program did improve indicators of growth over a four-month period. The study also demonstrated that there was no difference between those children who received the PSB or CSB as part of their monthly food rations. As a randomized trial, the results of this study support using a PSB supplement within food aid programs to improve nutritional impact.

\section{ACKNOWLEDGMENTS}

This study would not have been possible without the support of the public health workers in Senegal who work with Counterpart International. Their dedication to providing services to their community members allowed this study to be conducted. We also appreciate the confidence past and current Counterpart staff had with arranging the financial support for this study including David Cohen and Thoric Cederstrom. The authors greatly appreciate the editorial support provided by Michelle Gamber. 


\section{List of Abbreviations:}

PSB - potato-soy protein concentrate blend

CSB - corn-soy blend

MUAC - mid upper arm circumference

WAZ- weight-for-age z-score

WHZ - weight-for-height z-score

HAZ - length/height-for-age z-scores

USAID - United States Agency for International Development

WFP - The World Food Program

CPI - Counterpart International

MCHN - Maternal and Child Health Nutrition

IRB - Institutional Review Board

WHO - World Health Organization. 


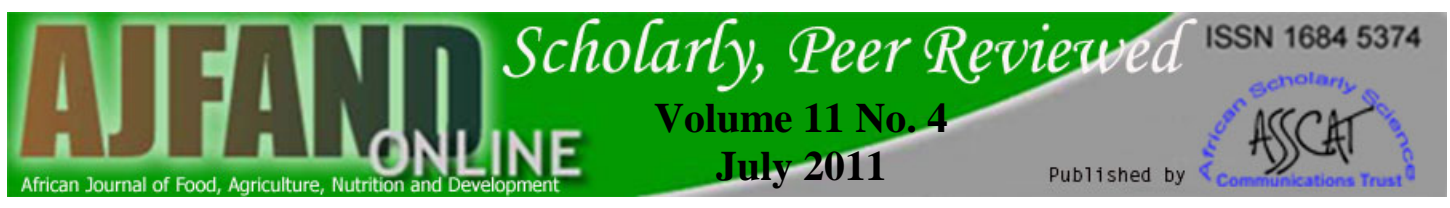

Table 1:Nutrient composition of rations

\begin{tabular}{lcc}
\hline Nutrient (per 100g) & Potato-Soy $^{1}$ & Corn Soya Blend $^{2}$ \\
\hline Energy (kcal) & 350.1 & 380 \\
Protein (g) & 18.5 & $14 \%$ \\
Fat (g) & 0.9 & $6 \%$ \\
Vitamin A (IU) & 1554.0 & $1414-1914$ \\
Thiamin (mg) & 0.128 & $0.108-0.147$ \\
Riboflavin (mg) & 0.448 & $0.380-0.515$ \\
Niacin (mg) & 4.8 & $4.1-5.5$ \\
Folate ( $\mu \mathrm{g})$ & 60.0 & $51-69$ \\
Vitamin C (mg) & 48 & $41-55$ \\
Vitamin B12 ( $\mu \mathrm{g})$ & 1.2 & $1.0-1.4$ \\
Iron (mg) & 8 & $7-9$ \\
Calcium (mg) & 100 & $84-115$
\end{tabular}

${ }^{1}$ Chemically determined by Purina ${ }^{\circledR}$.

${ }^{2}$ Recommended ranges from the World Food Program (http://foodquality.wfp.org). 


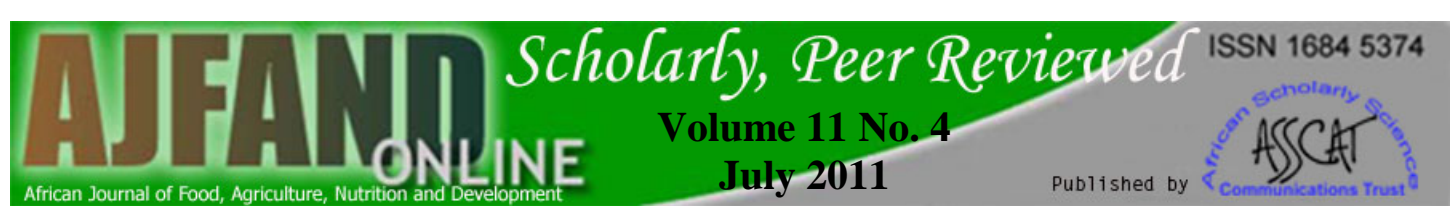

Table 2: Baseline characteristics with initial anthropometric measures

\begin{tabular}{lcccccc}
\hline & \multicolumn{2}{c}{ Weight } & \multicolumn{2}{c}{$\begin{array}{c}\text { Height } \\
\text { kg }\end{array}$} & \multicolumn{2}{c}{$\begin{array}{c}\text { MUAC } \\
\text { cm }\end{array}$} \\
\hline & PSB & CSB & PSB & CSB & PSB & CSB \\
\hline Sex & & & & & & \\
Boys & $11.2 \pm 1.3$ & $11.0 \pm 1.7$ & $89.5 \pm 6.0$ & $89.0 \pm 7.5$ & $14.0 \pm 0.9$ & $14.0 \pm 1.0$ \\
Girls & $10.6 \pm 1.5$ & $10.8 \pm 1.5$ & $86.8 \pm 7.4$ & $87.8 \pm 7.2$ & $14.0 \pm 0.9$ & $14.1 \pm 0.9$ \\
& & & & & & \\
Age & & & & & & \\
$<$ 24m & $9.2 \pm 0.8$ & $9.1 \pm 1.1$ & $79.4 \pm 3.2$ & $79.9 \pm 3.9$ & $13.9 \pm 0.6$ & $13.4 \pm 1.0$ \\
24-35m & $10.3 \pm 1.1$ & $10.1 \pm 1.1$ & $84.7 \pm 4.6$ & $84.2 \pm 4.5$ & $14.0 \pm 0.8$ & $14.0 \pm 0.8$ \\
36-47m & $11.5 \pm 0.9$ & $11.6 \pm 1.3$ & $91.3 \pm 4.1$ & $92.4 \pm 5.0$ & $14.3 \pm 0.9$ & $14.2 \pm 0.8$ \\
$\geq 48 m$ & $12.7 \pm 1.2$ & $12.6 \pm 1.0$ & $97.2 \pm 4.8$ & $97.5 \pm 3.1$ & $14.2 \pm 1.1$ & $14.2 \pm 1.1$ \\
& & & & & & \\
Diarrhea & & & & & & \\
Yes & $10.9 \pm 1.5$ & $10.7 \pm 1.4$ & $87.9 \pm 6.6$ & $87.1 \pm 6.5$ & $14.1 \pm 0.9$ & $14.0 \pm 1.1$ \\
No & $10.9 \pm 1.4$ & $11.0 \pm 1.7$ & $88.1 \pm 7.2$ & $89.4 \pm 7.8$ & $14.2+0.8$ & $14.1 \pm 0.8$ \\
& & & & & & \\
ARI & & & & & & \\
Yes & $11.1 \pm 1.5$ & $10.8 \pm 1.8$ & $89.2 \pm 7.4$ & $88.1 \pm 7.5$ & $14.0 \pm 0.9$ & $14.0 \pm 0.9$ \\
No & $10.8 \pm 1.4$ & $10.9 \pm 1.5$ & $87.3 \pm 6.6$ & $88.6 \pm 7.2$ & $14.2 \pm 0.8$ & $14.1 \pm 0.9$ \\
& & & & & & \\
Fever & & & & & & \\
Yes & $10.8 \pm 1.4$ & $10.9 \pm 1.6$ & $88.0 \pm 7.2$ & $88.5 \pm 7.4$ & $14.0 \pm 1.0$ & $14.0 \pm 0.9$ \\
No & $11.0 \pm 1.5$ & $10.9 \pm 1.6$ & $88.0 \pm 6.6$ & $88.2 \pm 7.2$ & $14.2 \pm 0.7$ & $14.1 \pm 0.9$ \\
\hline
\end{tabular}




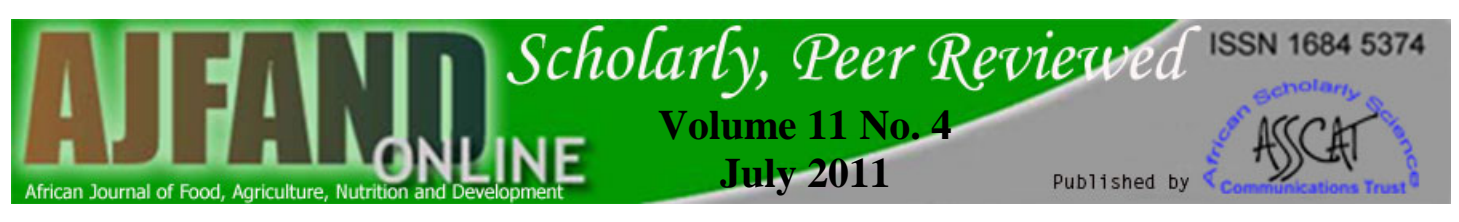

Table 3: Baseline characteristics with initial anthropometric z-scores

\begin{tabular}{|c|c|c|c|c|c|c|}
\hline & \multicolumn{2}{|c|}{$\begin{array}{c}\text { WAZ } \\
\text { z-score }\end{array}$} & \multicolumn{2}{|c|}{$\begin{array}{c}\text { HAZ } \\
\text { z-score }\end{array}$} & \multicolumn{2}{|c|}{$\begin{array}{c}\text { WHZ } \\
\text { z-score }\end{array}$} \\
\hline & PSB & CSB & PSB & CSB & PSB & CSB \\
\hline \multicolumn{7}{|l|}{ Sex } \\
\hline Boys & $-2.3 \pm 0.6$ & $-2.3 \pm 0.8$ & $-1.8 \pm 1.0$ & $-1.5 \pm 1.1$ & $-1.5 \pm 0.7$ & $-1.8 \pm 0.7$ \\
\hline Girls & $-2.3 \pm 0.6$ & $-2.2 \pm 0.6$ & $-1.8 \pm 1.0$ & $-1.7 \pm 1.0$ & $-1.5 \pm 0.7$ & $-1.7 \pm 0.6$ \\
\hline \multicolumn{7}{|l|}{ Age } \\
\hline$<24 \mathrm{~m}$ & $-2.0 \pm 0.6$ & $-2.3 \pm 0.8$ & $-1.7 \pm 0.9$ & $-1.6 \pm 1.2$ & $-1.5 \pm 0.6$ & $-1.8 \pm 0.7$ \\
\hline $24-35 \mathrm{~m}$ & $-2.2 \pm 0.7$ & $-2.3 \pm 0.7$ & $-1.5 \pm 1.2$ & $-1.6 \pm 1.0$ & $-1.5 \pm 0.7$ & $-1.5 \pm 0.6$ \\
\hline $36-47 \mathrm{~m}$ & $-2.3 \pm 0.6$ & $-2.2 \pm 0.7$ & $-1.9 \pm 1.0$ & $-1.6 \pm 1.2$ & $-1.6 \pm 0.7$ & $-1.7 \pm 0.6$ \\
\hline$\geq 48 \mathrm{~m}$ & $-2.3 \pm 0.6$ & $-2.3 \pm 0.6$ & $-1.8 \pm 1.0$ & $-1.7 \pm 0.7$ & $-1.7 \pm 0.7$ & $-1.7 \pm 0.8$ \\
\hline \multicolumn{7}{|l|}{ Diarrhea } \\
\hline Yes & $-2.3 \pm 0.6$ & $-2.2 \pm 0.7$ & $-1.7 \pm 1.1$ & $-1.6 \pm 1.0$ & $-1.6 \pm 0.7$ & $-1.6 \pm 0.7$ \\
\hline No & $-2.2 \pm 0.6$ & $-2.3 \pm 0.7$ & $-1.7 \pm 1.1$ & $-1.6 \pm 1.1$ & $-1.5 \pm 0.6$ & $-1.7 \pm 0.6$ \\
\hline \multicolumn{7}{|l|}{ ARI } \\
\hline Yes & $-2.1 \pm 0.6$ & $-2.2 \pm 0.8$ & $-1.5 \pm 1.0$ & $-1.6 \pm 1.1$ & $-1.6 \pm 0.7$ & $-1.6 \pm 0.6$ \\
\hline No & $-2.3 \pm 0.6$ & $-2.3 \pm 0.6$ & $-1.8 \pm 1.1$ & $-1.6 \pm 1.0$ & $-1.5 \pm 0.6$ & $-1.6 \pm 0.7$ \\
\hline \multicolumn{7}{|l|}{ Fever } \\
\hline Yes & $-2.3 \pm 0.6$ & $-2.2 \pm 0.7$ & $-1.7 \pm 1.1$ & $-1.5 \pm 1.1$ & $-1.6 \pm 0.7$ & $-1.6 \pm 0.7$ \\
\hline No & $-2.2 \pm 0.6$ & $-2.3 \pm 0.6$ & $-1.7 \pm 1.0$ & $-1.7 \pm 1.0$ & $-1.5 \pm 0.5$ & $-1.6 \pm 0.6$ \\
\hline
\end{tabular}




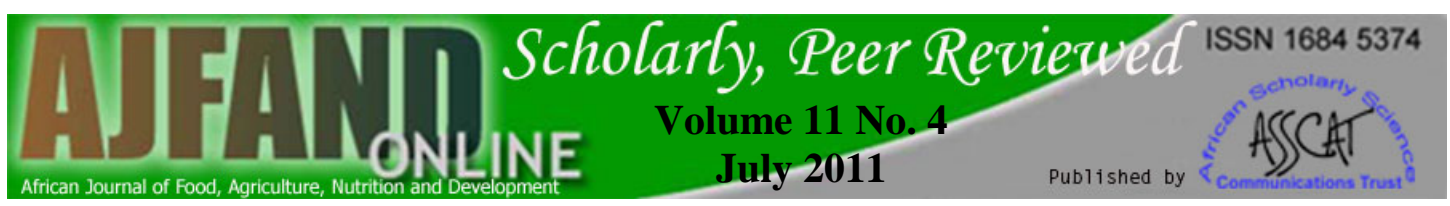

Table 4: Baseline characteristics of subest of children with $100 \%$ attendance

\begin{tabular}{|c|c|c|}
\hline & \multicolumn{2}{|c|}{ Supplement Groups } \\
\hline & CSB (n 145) & PSB (n 135) \\
\hline Baseline Characteristics & mean $\pm 1 \mathrm{SE}$ & mean $\pm 1 \mathrm{SE}$ \\
\hline Age (months) & $35.7 \pm 0.85$ & $36.0 \pm 0.86$ \\
\hline MUAC (cm) & $14.0 \pm 0.07$ & $14.1 \pm 0.07$ \\
\hline WAZ & $-2.46 \pm 0.05$ & $-2.45 \pm 0.05$ \\
\hline HAZ & $-1.58 \pm 0.08$ & $-1.71 \pm 0.10$ \\
\hline WHZ & $-1.92 \pm 0.06$ & $-1.84 \pm 0.06$ \\
\hline $\mathrm{WAZ} \leq-2.00(\%)$ & 78.6 & 80.0 \\
\hline $\mathrm{HAZ} \leq-2.00(\%)$ & 29.0 & 37.0 \\
\hline WHZ $\leq-2.00(\%)$ & 46.2 & 45.2 \\
\hline Male (\%) & 43.4 & 46.7 \\
\hline \multicolumn{3}{|l|}{ Presenting with: } \\
\hline Respiratory illness (\%) & 22.1 & 29.6 \\
\hline Diarrhea (\%) & 37.9 & 34.1 \\
\hline Fever (\%) & $66.9 *$ & $51.1^{*}$ \\
\hline
\end{tabular}

$* \mathrm{p}<0.05$ 


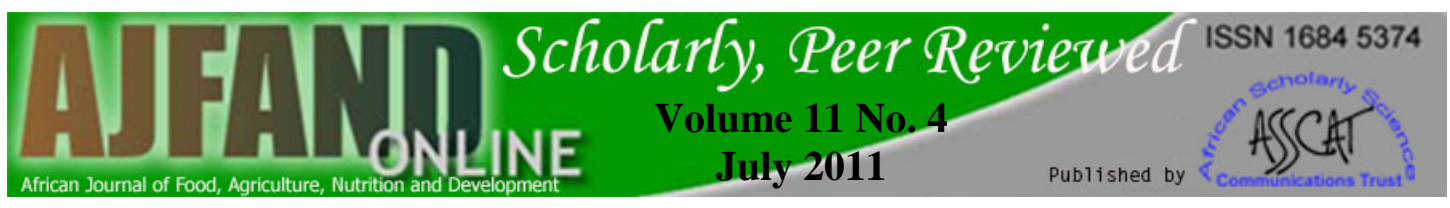

Table 5: Baseline and final follow-up at 4 months in children completing $100 \%$ of visits

Anthropometric Measurements

\begin{tabular}{|c|c|c|c|c|}
\hline Study Groups (n) & $\begin{array}{c}\text { WHZ } \\
\text { Mean } \pm 1 \text { SE }\end{array}$ & $\begin{array}{c}\text { WAZ } \\
\text { Mean } \pm 1 \text { SE }\end{array}$ & $\begin{array}{c}\text { HAZ } \\
\text { Mean } \pm 1 \text { SE }\end{array}$ & $\begin{array}{l}\text { MUAC }(\mathrm{cm}) \\
\text { Mean } \pm 1 \mathrm{SE}\end{array}$ \\
\hline \multicolumn{5}{|l|}{ Total (280) } \\
\hline Baseline & $-1.89 \pm 0.04$ & $-2.46 \pm 0.04$ & $-1.64 \pm-0.06$ & $14.10 \pm 0.05$ \\
\hline 4-Month & $-1.62 \pm 0.04$ & $-2.21 \pm 0.04$ & $-1.55 \pm-0.06$ & $14.18 \pm 0.05$ \\
\hline Difference & $0.26 \pm 0.04^{\S}$ & $0.24 \pm 0.03^{\S}$ & $0.09 \pm 0.02^{\S}$ & $0.08 \pm 0.04^{*}$ \\
\hline \multicolumn{5}{|l|}{ CSB (145) } \\
\hline Baseline & $-1.92 \pm 0.06$ & $-2.46 \pm 0.05$ & $-1.58 \pm 0.08$ & $14.08 \pm 0.08$ \\
\hline 4-Month & $-1.64 \pm 0.05$ & $-2.21 \pm 0.05$ & $-1.51 \pm 0.08$ & $14.19 \pm 0.07$ \\
\hline Difference & $0.28 \pm 0.05^{\S}$ & $0.25 \pm 0.04^{\S}$ & $0.07 \pm 0.03^{*}$ & $0.10 \pm 0.05$ \\
\hline \multicolumn{5}{|l|}{ PSB (135) } \\
\hline Baseline & $-1.85 \pm 0.06$ & $-2.45 \pm 0.05$ & $-1.71 \pm 0.10$ & $14.12 \pm 0.08$ \\
\hline 4-Month & $-1.60 \pm 0.06$ & $-2.22 \pm 0.05$ & $-1.59 \pm 0.09$ & $14.18 \pm 0.08$ \\
\hline Difference & $0.24 \pm 0.05^{\S}$ & $0.24 \pm 0.04^{\S}$ & $0.11 \pm 0.03^{\S}$ & $0.06 \pm 0.06$ \\
\hline
\end{tabular}

$\S \mathrm{p}$ value $<0.001$ using paired t-test between baseline and follow-up measures

$*$ p value $<0.05$ using paired t-test between baseline and follow-up measures 


\section{REFERENCES}

1. UNICEF. State of the World's Children Report 2009. United Nations Children's Fund, New York, 2008.

2. Morris SS, Black RE and L Tomaskovic Predicting the distribution of underfive deaths by cause in countries without adequate vital registration systems. International Journal of Epidemiology 2003; 32: 1041-1051.

3. Idohou-Dossou N, Wade S, Guiro AT, Sarr CS, Diaham B, Cissé D, Beau JP, Chappuis P, Hoffman D and D Lemonnier Nutritional status of preschool Senegalese children: long-term effects of early severe malnutrition. British Journal of Nutrition 2003; 90: 1123-32.

4. Badji MS and D Boccanfuso Nutritional health of the children in Senegal: a comparative analysis. Journal of African Development 2008; 10: 71-103.

5. Black RE, Allen LH, Bhutta ZA, Caulfield LE, de Onis M, Ezzati M, Mathers $\mathbf{C}$, Rivera $\mathbf{J}$ and the Maternal and Child Undernutrition Study Group Maternal and child undernutrition: global and regional exposures and health consequences. Lancet 2008; 371: 243-60.

6. Sadler K, Myatt M, Feleke $\mathbf{T}$ and S Collin A comparison of the programme coverage of two therapeutic feeding interventions implemented in neighbouring districts of Malawi. Public Health Nutrition 2007; 10: 907-13.

7. Awokuse TO Assessing the impact of food aid on recipient countries: a survey. Rome: ESA Working paper No. 06-11, Agricultural and Development Economics Division, The Food and Agriculture Organization of the United Nations, New York, 2006.

8. USAID. Annex E. Public Law 480 Title II Eligible Commodity List 2009 Food for Peace Act Program Polices and Proposal Guidelines, Washington DC.[http://www.usaid.gov/our_work/humanitarian_assistance/ffp/annexe_vacl.d oc]Accessed August 2009.

9. Allen LH and D Gilliard What works? A review of the efficacy and effectiveness of nutrition interventions. Asian Development Bank, Manila: ACC/SCN, Geneva, 2001.

10. The PLoSMedicine Editors. Scaling up international food aid: Food delivery alone cannot solve the malnutrition crisis. PLoS Med 2008; 5: 1525-1527.

11. World Vision. Acting on AIDS: Broken Bread Program Guide. Federal, Washington.[http://www.worldvision.org/aoa.nsf/0783167f5da26bf6872570a20 0775036/c88dc4aa3b4ef1ba8825733e001217c5/\$FILE/Broken\%20Bread\%20G uide.pdf] Accessed August 2009. 


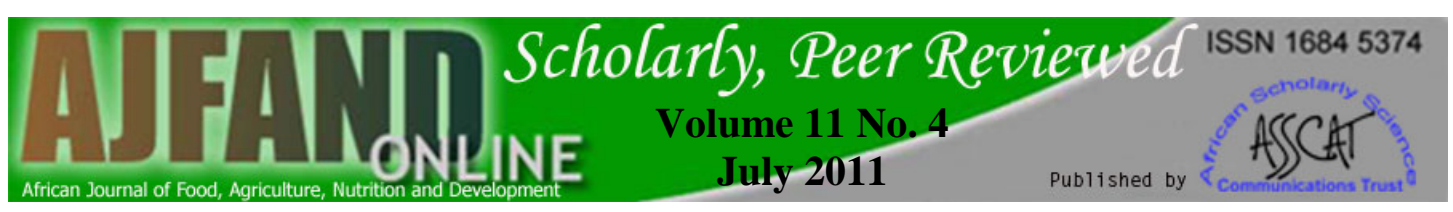

12. WHO. Training Course on Child Growth Assessment.World Health Organization, Geneva, 2008.

13. Epidemiology Program Office. Epi Info ${ }^{\mathrm{TM}}$ users' manual, version 5.Centers for Disease Control and Prevention, Atlanta, 1990.

14. Boutron I, Moher D, Altman Dg, Schulz KF, Ravaud P and the CONSORT Group Extending the CONSORT statement to randomized trials of nonphamacologic treatment: explanation and elaboration. Annals of Internal Medicine 2008; 148: 295-309.

15. Abdulai A, Barrett $\mathbf{C B}$ and $\mathbf{J}$ Hoddinott Does food aid really have disincentive effects? New evidence from sub-Saharan Africa.World Development 2005; 33: 1689-1704.

16. Gebremedhin $\mathbf{B}$ and SM Swinton Reconciling food-for-work project feasibility with food aid targeting in Tigray, Ethiopia. Food Policy 2001; 26: 85-95.

17. Rivera JA and JP Habicht Effect of supplementary feeding on the prevention of mild-to-moderate wasting in conditions of endemic malnutrition in Guatemala. Bull World Health Organization 2002; 80: 926-32.

18. Ruel MT, Menon P, Habicht JP, Loechl C, Bergeron G, Pelto G, Arimond M, Maluccio J, Michaud $L$ and B Hankebo Age-based preventive targeting of food assistance and behaviour change and communication for reduction of childhood undernutrition in Haiti: a cluster randomised trial. Lancet 2008; 371: 588-95.

19. Cogill B Anthropometric Indicators Measurement Guide. Food and Nutrition Technical Assistance Project, Academy for Educational Development, Washington DC, 2003.

20. Bryce J, Coitinho D, Darnton-Hill I, Pelletier D, Pinstrup-Andersen $\mathbf{P}$ and the Maternal and Child Undernutrition Study Group Maternal and child undernutrition: effective action at national level. The Lancet 2008; January 17: 65-81. [Published Online, DOI:10.1016/S0140- 6736(07)61694-8].

21. De Pee S and MW Bloem Current and potential role of specially formulated foods and food supplements for preventing malnutrition among 6-23 months old and treating moderate malnutrition among 6-59 months old children. WHO, UNICEF, WFP and UNHCR Consultation on the Dietary Management of Moderate Malnutrition in Under-5 Children by the Health Sector, 2008.

22. WHO/FAO/SCN/UNICEF. Community-based management of severe acute malnutrition.A Joint Statement by the World Health Organization, the World Food Programme, the United Nations System Standing Committee on Nutrition and the United Nations Children's Fund, Geneva, 2007. 
23. Hossain A and M Miah Post harvest losses and technical efficiency of potato storage systems in Bangladesh. Bangladesh Agricultural Research Institute, 2009.

24. Lenné JM and AF Ward Improving the efficiency of domestic vegetable marketing systems in east Africa. Outlook on Agriculture 2010; 39: 31-40.

25. Bechoff A, Tomlins K, Dhuique-Mayer C, Rand D, and A Westby On-farm evaluation of the impact of drying and storage on the carotenoid content of orange-fleshed sweet potato (Ipomeabatata Lam.) International Journal of Food Science \& Technology 2011; 46: 52-60.

26. Ball TM and DL Taren Nutritional Screening of Under-Fives in Malawi: The Road-To-Health Card vs Arm Circumference and Maternal Reporting of Illness. Journal of Tropical Pediatrics 1995; 41: 250-252. 